\title{
Experienciar, suturar e sobrejustapor sentidos na teoria e na crítica da imagem: dois possíveis desvios estratégicos
}

CRISTIAN POLETTI MOSSI

MARILDA OLIVEIRA DE OLIVEIRA

Resumo

O artigo propõe-se a pensar dois possíveis desvios estratégicos na atividade de experienciar, suturar e sobrejustapor sentidos no campo da teoria e da crítica da imagem. Primeiramente demarco de que modo emprego as palavras desvio, sutura e sobrejustaposição para depois propor o 'desvio estratégico 1' pautado pela experiência do Corpo sem Órgãos (CsO) pensada por Deleuze \& Guatarri (1996), a continuação proponho o 'desvio estratégico 2' pautado por Canclini (2007) com suas inferências acerca do campo da antropologia na contemporaneidade, para finalmente pensar a atividade da crítica da imagem na atualidade.

Palavras-chave:

Corpo sem órgãos $(\mathrm{CsO})$, etnografia da imagem, teoria e crítica da imagem 


\title{
Experiencing, suturing and over- juxtaposing directions on theory and critics of the image: two possible strategic deviations
}

\author{
CRISTIAN POLETTI MOSSI \\ MARILDA OLIVEIRA DE OLIVEIRA
}

\section{Abstract}

The present paper aims at considering two possible deviations in the activity of strategic experience, suturing and over-juxtapose directions in the field of theory and criticism of the image. Former I outline in which way I employ the terms deviation, suture and over-juxtaposition to propose 'a strategic deviation 1' guided by the experience of the Corpo Sem Órgãos (CSO) (Body without Organs) conceived by Deleuze \& Guattari (1996). Latter I propose the 'strategic

Keywords: Body without organs (CSO), ethnography image, theory and criticism of the image deviation 2' guided by Canclini (2007) with their inferences about the field of anthropology in contemporary times, to finally think about the activity of critical image nowadays. 


\section{Desvio para o princípio}

Imagens nos enfrentam. E ao enfrentar-nos possibilitam formulações subjetivas das mais diversas ordens, lançam fios para a tessitura eterna de nós mesmos. O que vemos e o modo como nos vemos (ou ainda a outreidade nos vê) estão intrinsecamente relacionados. Ver é desdobrar afecções relacionadas ao que é visto, construindo em si possibilidades perceptivas que nos atravessam e nos constroem. Ver é suturar e sobrejustapor sentidos em e a partir de imagens.

A palavra sutura, trazida da linguagem médica e relacionada à ação de costurar os lábios de uma ferida, ou ainda produzir inserções de partes umas às outras, constitui-se numa metáfora possível de ser pensada ao refletirmos acerca da ação de experienciarmos produções e mobilizações de sentidos e significados em e a partir de imagens. A sutura é algo que provoca marcas, perfaz unidades (ainda que provisórias), possibilita acoplamentos que não são indestrutíveis. As mutilações sígnicas, as refragmentações de partes podem acontecer a qualquer momento, sendo refeitas e novamente suturadas.

A sobrejustaposição (licença poética resultante da união sobrejustaposta nela própria das palavras sobreposição e justaposição) evidencia o ato de sobrepor e justapor ao mesmo tempo, no mesmo ato e com a mesma intensidade, sentidos e imagens, sentidos e sentidos e/ou imagens e imagens ${ }^{3}$. Designa o processo e o resultado da 'coleta', 'combinação' e 'descarte' que pode ocorrer a partir de discursos de diversas ordens (textuais, orais, visuais, entre outros) e que oferece um resultado provisório na produção de possibilidades a partir dos mesmos. Tal (des)ordem lingüística permite atrelar o pensamento à imagem, deixar que ele faça parte dela própria e estabeleça entremeios, vias, canais, superfícies e percursos 
orgânicos na relação sobreposta e justaposta de camadas perceptivas/experimentativas.

Nessa perspectiva, suturamos e sobrejustapomos sentidos e imagens quando ao experienciarmos as mesmas, estamos habitando e possibilitando seus significados. Estamos pulverizando a partir delas possibilidades infinitas de desdobramento e deixando que tais potências nos atravessem e nos configurem. Muito embora por vezes procuremos significados fora de nós, tais conjecturas só são possíveis a partir de estilhaçamentos subjetivos que ocorrem num espelhamento contínuo o qual opera em um fluxo de troca constante entre o que nos vê e o que é visto.

Segundo Didi-Huberman (1998) ganhamos algo quando vemos alguma coisa, no sentido que apreendemos o que vemos e tal possibilidade visível passa a fazer parte de nós. Permeado por discursos de diversas ordens, mas especialmente os visuais, o sujeito atual se vê e se reformula constantemente. Podemos dizer ainda que a própria crítica e as teorias que embasam as inter-relações entre imagens e subjetividades podem ser amplamente repensadas e redimensionadas. O que me proponho a pensar aqui são justamente alguns percursos possíveis na experimentação de imagens e na própria produção da crítica e das teorias da arte e das imagens frente ao contexto contemporâneo, ao suturarmos ou sobrejustapormos sentidos a partir de tais construções imagéticas.

Se desse modo estamos partindo do pressuposto que imagens nos constituem enquanto subjetividades em constante reformulação, ou seja, que são parte de nossos constantes e múltiplos percursos formativos, como podemos pensá-las em meio a invenções de caminhos possíveis? Caminhos não necessariamente mais facilitados, tampouco menos íngremes ou menos perigosos, mas caminhos alternativos que produzem experiências e que, por sua vez, produzem sujeitos, corpos, produzem modos de ser, oferecem elementos para a compilação das mais variadas suturas e sobrejustaposições.

Em meio à essa perspectiva, a ideia do desvio nos lança a possibilidade de um caminho que foge à regra usual. É uma viabilidade de percurso que se interpõe ao trajeto cursado permanentemente e cotidianamente. É um recurso, uma opção dentre tantas muitas. É um trajeto que não necessariamente nos leva mais facilmente onde queremos chegar (a produção de sentidos em e a partir de imagens), mas "está aí", à espreita de possíveis andantes. Não é uma opção melhor, nem tampouco mais adequada ou menos perigosa, mas é uma estratégia para quem assim se disponibiliza. 
A seguir apresento duas possibilidades de caminho os quais chamarei de desvios estratégicos. Caminhos enquanto estratégias que oferecem bifurcações, outros tantos cruzamentos, outras tantas passagens, outros tantos atalhos que podem abrir-se ainda em muitos outros. Um deles que atravessaremos juntamente com Deleuze \& Guattari (1996), pensando a experiência do enfrentamento de imagens (da arte, ou não) em articulação com a prática do Corpo sem Órgãos (CsO) e outro que passearemos juntamente com Canclini (2007), pensando uma produção crítica e/ou teórica da arte e das imagens enquanto antropologia/etnografia.

\section{Desvio estratégico 1: Um Corpo sem Órgãos ( $\mathrm{CsO})$ para experienciar, suturar e sobrejustapor imagens}

Porque o $\mathrm{CsO}$ é tudo isso: necessariamente um Lugar, necessariamente um Plano, necessariamente um Coletivo (agenciando elementos, coisas, vegetais, animais, utensílios, homens, potências, fragmentos de tudo isto, porque não existe 'meu' corpo sem órgãos, mas 'eu' sobre ele, o que resta de mim, inalterável e cambiante de forma, transpondo limiares) (DELEUZE; GUATTARI, 1996, p.24).

Corpo, órgãos, organismo. O dentro e o fora do corpo em estado de diálogo e experimentação. Deleuze \& Guattari (1996) propõem a experiência de criar para si um Corpo sem Órgãos, não no sentido de ir contra e desfazer o próprio corpo ou os próprios órgãos, mas sim o organismo. Fraturar o sistema linear e hierarquizado postulado e reproduzido pelo organismo, o qual propõe fluxos pelo que lhe falta (perspectiva psicanalítica), não pelo que deseja, e assim criar um Corpo sem Órgãos que possa ser habitado enquanto experiência frente ao mundo.

Desse modo,

Desfazer o organismo nunca foi matar-se, mas abrir o corpo a conexões que supõem todo um agenciamento, circuitos, conjunções, superposições e limiares, passagens e distribuições de intensidade, territórios e desterritorializações (...) (DELEUZE; GUATTARI, 1996, p.22)

O desejo configura-se enquanto a força imanente do Corpo sem Órgãos, vetor de agenciamentos de toda ordem. Deleuze \& Guattari (1996, p.16) propõem um desejo que se 
preenche "de si mesmo e suas contemplações, fato que não implica falta alguma, impossibilidade alguma" tal como predizia a psicanálise com Freud e a sua teoria do inconsciente.

Segundo Deleuze; Guattari (1996, p.9) o Corpo sem Órgãos não se configura enquanto uma noção ou um conceito, "mas antes uma prática, um conjunto de práticas". Um plano onde residem intensidades capazes de agenciar coisas à sua maneira, utilizando outra lógica que não a orgânica, que não a da dependência. A ele "não se chega, não se pode chegar, nunca se acaba de chegar (...), é um limite”.

Mas como pensar tal experiência proposta a partir do trabalho com (a experienciação, suturação e sobrejustaposição de) sentidos e imagens? O que seria possível de ser produzido ao implicar esse tipo de experimentação?

Como colocam os autores

Onde a psicanálise diz: Pare, reencontre o seu eu, seria preciso dizer: vamos mais longe, não encontramos ainda nosso $\mathrm{CsO}$, não desfizemos ainda suficientemente nosso eu. Substituir a anamnese pelo esquecimento, a interpretação pela experienciação (DELEUZE; GUATTARI, 1996, p.11).

Tal como o masoquista citado por Deleuze e Guattari (1996, p.12) que através de seu ato de perversão ao organismo busca na dor "as populações, as matilhas, os modos do masoquista-rei no deserto que ele faz nascer e crescer", busco aqui a experimentação desse corpo não orgânico, vazio dos fantasmas psicanalíticos, para adentrar e perfazer suturas, sobrejustaposições e a experienciações da produção de significados e diálogos entre sentidos e imagens.

Desfazer meu próprio eu para adentrar às imagens. Costurá-las, rasgá-las, perfazê-las, atravessá-las, desdobrá-las enquanto eu próprio rasgo-me e (re)costuro-me, dobro-me e desdobro-me a fim de provocar espaçamentos e novas/provisórias visualidades e visibilidades. Entender que os sentidos não habitam as imagens, tampouco eu, mas o entre que se cria ao enfrentá-las e ao combiná-las com outros dispositivos (visuais, textuais, orais, conceituais).

Deleuze; Guattari (1996, p. 12-13) inferem que

Em suma, entre um $\mathrm{CsO}$ de tal ou qual tipo e o que acontece nele, há uma relação muito particular de síntese ou de análise: síntese a priori onde algo vai ser necessariamente produzido sobre tal modo, mas não se sabe o que vai ser produzido; 
análise infinita em que aquilo que é produzido sobre o $\mathrm{CsO}$ já faz parte da produção deste corpo, já está compreendido nele, sobre ele, mas ao preço de uma infinidade de passagens, de divisões e de sub-produções.

Nesse sentido, a sutura e a sobrejustaposição designam aqui a ação de costurar, sobrepor e justapor imagens e os sentidos aguçados por elas ao mesmo tempo, entendendo que tais sentidos problematizam e criam outras tantas imagens mentais $^{4}$ no espectador que efetiva esta atividade, sem preocupar-se de antemão com que tipo de resultado será possível a partir dessa ação. Há, portanto, a justaposição (através da sutura) de imagens e sentidos presentes entre espectador e visualidade, bem como a sobreposição de camadas de sentido que encontram-se nos diversos modos de ver e pensar tais imagens que estão em constante estado de devir.

Portanto,

Trata-se de criar um corpo sem órgãos ali onde as intensidades passem e façam com que não haja mais nem eu nem o outro, isto não em nome de uma generalidade mais alta, de uma maior extensão, mas em virtude de singularidades que podem mais ser consideradas pessoais, intensidades que não se pode mais chamar de extensivas. O campo de imanência não é interior ao eu; mas também não vem de um eu exterior ou de um não-eu. Ele é antes como o Fora absoluto que não conhece mais o eu, porque o interior e o exterior fazem igualmente parte da imanência na qual eles se fundiram (DELEUZE; GUATTARI, 1996, p 18).

Na tentativa de criar para si um Corpo sem Órgãos com o intuito de experienciar, suturar e sobrejustapor imagens, subjetividade, visualidade e pensamento passam a fazer parte de uma coisa só, do mesmo corpo por onde atravessam-se inúmeras intensidades de desejo as quais possibilitam produzir e combinar sentidos, além de outras imagens que se transformam constantemente nesse processo.

\section{Desvio estratégico 2: A crítica/teoria da imagem enquanto etnografia}

(...) fazer antropologia caracteriza-se, (...) pela tensão entre estar lá e estar aqui, pôr em relação o que é diferente com o que é próprio, entendido como outra diferença (CANCLINI, 2007, p.143). 
Inicio este segundo desvio estratégico com base neste fragmento de Canclini, o qual pode nos ajudar a pensar algumas questões tensionadas entre os territórios ocupados pelo antropólogo/etnógrafo e pelo teórico/crítico de arte e da imagem em seus exercícios profissionais no contexto contemporâneo. De antemão, podemos destacar que, assim como o antropólogo/etnógrafo não se utiliza de um olhar neutro em seu discurso, mas remaneja seu lugar de fala entre o eu (visto pelo olhar do outro) e o outro (visto pelo seu olhar), assim também o teórico/crítico que possibilita a produção de sentidos a partir de imagens de diversas ordens, inclusive da arte o faz com seu instrumental de trabalho que não são os grupos sociais/culturais como no caso do antropólogo/etnógrafo, mas sim a produção imagética legitimada e entendida enquanto artística por determinado contexto ou não.

Portanto me pergunto, em que medida podem se tocar as ações desses profissionais no contexto contemporâneo? O que significaria propor uma antropologia, ou uma etnografia da obra de arte e das imagens?

Se aqui estamos pensando a etnografia segundo seu conceito denotativo, estamos a entendendo enquanto uma das partes do estudo antropológico que objetiva elaborar os dados obtidos em uma pesquisa de campo, ou ainda o estudo descritivo que pretende dar visibilidade aos diversos aspectos sociais e culturais de um determinado grupo social. Por analogia, entendemos o teórico/crítico da arte enquanto profissional que através de suas aspirações pessoais, do instrumental ofertado pela linguagem e de determinados aprofundamentos teóricos, pretende dar a ver (no sentido de propor) um tipo específico de apreensão da produção artística e imagética. Nesse sentido, podemos ponderar inúmeros pontos de contato entre tais atividades.

Canclini (2007, p.143) propõe novos modos de ver o trabalho antropológico na contemporaneidade. Para este teórico, ser antropólogo significa

estudar a interculturalidade em sociedades complexas ou processos de interação entre várias sociedades, buscando entender a imbricação do econômico e do simbólico a partir da diversidade de comportamentos e representações.

Ou seja, além de aprofundar-se em questões específicas de cada grupo social/cultural estudado, o antropólogo tam- 
bém se ocupa das diversas tensões e inter-relações de fatores que se entrelaçam no mundo contemporâneo para formar o que chamamos de interculturalidade. O teórico/crítico da arte e da imagem, por sua vez, não ocupa-se de grupos sociais/ culturais mas dos imbricamentos, dos cruzamentos que são possíveis entre a prática da teoria (produções teóricas acerca das obras e das imagens no contexto onde elas emergem) e a teoria posta em prática (imagens e obras artísticas que partem não necessariamente de teorias, mas suscitam teorias e práticas discursivas enquanto fenômenos), além de pensar articulações entre as próprias imagens/obras.

Dentro dessa perspectiva, a subjetividade, as experiências anteriores, enfim, o próprio recorte político e de olhar do pesquisador referendando o grupo social/cultural estudado ou as produções destes grupos (como as visualidades), são pontos de atravessamento no momento em que há uma organização dos escritos que perfazem o resultado (parcial) de sua investigação.

Como relata Canclini (2007, p.132).

Hoje, sabemos que o que um antropólogo declara ter encontrado em campo está condicionado pelo que se disse ou não se disse previamente sobre este lugar, pelas relações que estabelece com o grupo que estuda e com os diferentes setores do mesmo, ou pelo que quer demonstrar - sobre este grupo e sobre si mesmo - à comunidade acadêmica para a qual escreve, pela sua posição (dominante ou pretendente) no campo antropológico, pelo manejo mais ou menos hábil das táticas discursivas com que pode conseguir tudo isso.

Nessa mesma perspectiva Deleuze (2001, p.94) comenta que o sujeito (portador e reinventor, propositor daquilo que chamamos de contexto/mundo) "reflete e se reflete". Ou seja, "daquilo que o afeta em geral, ele extrai um poder independente do exercício atual, isto é, uma função pura, e ele ultrapassa sua parcialidade própria”. Para o autor "o sujeito inventa, ele é artificioso".

Ao passo que propõe coisas no e para os territórios nos quais habita, o sujeito reinventa-se a si próprio, ordena-se parcialmente e transitoriamente. Como pressupõe Greiner (2005, p. 42) “(...) o que se costuma chamar de 'si-mesmo' não diz respeito apenas ao interior de um corpo, mas às conexões do interior com o exterior". Além de reinventar constantemente seu corpo-si e assim transformar o entorno, coloca em estado de tensão e diálogo o dentro e o fora de seu ser enquan- 
to existência num movimento em que o dentro (pensamento e subjetividade) possibilita intermináveis foras que expandem o ser em seu sentido amplo.

Assim, o sujeito

se define por e como um movimento, movimento de desenvolver-se a si mesmo. O que se desenvolve é sujeito. Aí está o único conteúdo que se pode dar à idéia de subjetividade: a mediação, a transcendência. Porém, cabe observar que é duplo o movimento de desenvolver-se a si mesmo ou de devir outro: o sujeito se ultrapassa, o sujeito se reflete (DELEUZE 2001, p. 94).

As reflexões e experiências do pensamento possibilitadas por dispositivos (como as imagens da arte), além de constituírem os sujeitos e seus contextos, servem enquanto interlocutores de vivências e espelhamentos. Assim, o sujeito, as subjetividades e aquilo que os rodeia advém dos trânsitos que remetem a sortilégios do ver e dos reflexos que conduzem ao auto-olhar-se.

Nesse sentido, o que é produzido tanto pelo antropólogo, quanto pelo teórico/crítico da arte e das imagens não pode ser considerado como 'a verdade' ou ainda como 'a realidade', partindo da instância que criam através da linguagem sistemas de mediação e significação do mundo, os quais referem-se a 'possíveis verdades', ou a 'possíveis realidades', de acordo com diversos aspectos que o definem também enquanto alteridade (o outro), diante e em relação ao objeto de estudo. Tais produções referem-se mais a um diálogo entre 'verdades' - por exemplo, a do grupo social/cultural (no caso do antropólogo/ etnógrafo) e a da obra (no caso do teórico/crítico da arte e da imagem) - que propriamente uma tentativa de esclarecimento ou de aproximação com a veracidade acerca dos fatos.

Para tanto, Canclini (2007, p.133) propõe três operações para serem consideradas ao conduzir um trabalho antropológico comprometido com a demanda atual para esta área e que podem de algum modo fazer-nos refletir acerca do trabalho teórico/crítico no campo da arte e das imagens:

a) incluir na exposição das investigações a problematização das interações culturais e políticas do antropólogo com o grupo estudado; b) suspender a pretensão de abarcar a totalidade da sociedade examinada e prestar atenção à fraturas, à contra- 
dições. Aos aspectos inexplicados, às múltiplas perspectivas sobre os fatos; c) recriar esta multiplicidade no texto, oferecendo a pluralidade de vozes das manifestações encontradas, transcrevendo diálogos ou reproduzindo o caráter dialógico da construção de interpretações. Em vez do autor monológico, autoritário, busca-se a polifonia, a autoria dispersa. (CANCLINE, 2007, p. 133)

Dentro do primeiro aspecto, percebemos a possibilidade de pensarmos uma teoria e uma crítica da arte e das imagens onde seu produtor apareça enquanto sujeito que concentra em si um lugar de fala, uma perspectiva própria e que considera que sua produção é parte de um recorte, de uma seleção. Já, adentrando no segundo aspecto, por ser somente um fragmento do todo que é a produção artística e imagética, entendemos que tanto a teoria quanto a crítica da arte e das imagens podem estar mais atentas à experiência numa relação mais fluída e espacial, ao contrário de linear e temporal, para assim, pensando já no terceiro aspecto, produzir um discurso que possa ser mais propositivo e menos prescritivo, onde são lançados questionamentos e problematizações mais que a tentativa de tradução dos significados das obras e das imagens, ou de subjugar algumas em detrimento de outras hierarquicamente.

Assim, propõe-se uma etnografia da obra de arte e das imagens, sobretudo, enquanto um dispositivo amplificador de experiências múltiplas, variadas, que suscitam no espectador uma etnografia de si, onde há um contínuo remanejamento de seus territórios perceptivos, interpelando-o acerca dele próprio enquanto produtor de sentidos a partir da perspectiva que ocupa no exercício do ver.

Além disso, uma etnografia da obra de arte e das imagens se ocupa das inter-relações que são possíveis de serem tecidas entre as visualidades e seus contextos de origem, entre os impactos causados por elas nos mais variados territórios interpretativos que as recebem, bem como das relações dialógicas entre elas, entre as intersignificalidades que expressam um entre prenhe de sentidos múltiplos.

Busca-se, portanto, propor uma antropologia/etnografia das obras de arte e das imagens de modo não isolado, mas de forma a problematizar tensões e inter-relações, onde as visualidades ocupam o lugar do outro frente a 'mim', mas também 'eu' ocupo o lugar do outro frente às imagens. A partir 
dessa breve conjectura, mapas de sentido se desenham entre visualidades, sentidos produzidos, teorias e reflexões que são oriundas dessas múltiplas conjunções.

\section{Referências}

CANCLINI, Néstor García. Diferentes, desiguais e desconectados: mapas da interculturalidade. 2. Ed. Rio de Janeiro: Editora UFRJ, 2007.

DELEUZE, Gilles; GUATTARI, Félix. Mil platôs: capitalismo e esquizofrenia, vol. 3. Rio de Janeiro: Ed. 34, 1996.

DIDI-HUBERMAN, Georges. O que vemos, o que nos olha. São Paulo: Ed. 34, 1998.

GREINER, Christine. O corpo: pistas para estudos indisciplinares. São Paulo: Annablume, 2005.

NOTAS

1. Tal licença poética que trago para problematizar neste artigo foi cunhada por mim e melhor aprofundada em minha dissertação de mestrado desenvolvida no Programa de Pós-Graduação em Artes Visuais (PPGART) da Universidade Federal de Santa Maria (U̧FSM), sob orientação da Profa. Dra. Marilda Oliveira de Oliveira, na linha de pesquisa Arte e Cultura, intitulada 'Possíveis territorialidades e a produção crítica da arte - suturas e sobrejustaposições entre vestes sem corpos e corpos sem vestes'. Nessa pesquisa, defendida em março de 2010, propus-me a tecer relações entre as obras das artistas contemporâneas Claudia Casarino e Vanessa Beecroft, as quais apresentam na poética de algumas de suas obras 'vestes sem corpos' e 'corpos sem vestes' respectivamente, o que resultaram em produções verbais e visuais (as quais chamei de suturas e sobrejustaposições), para falar do contexto atual da produção crítica da arte.

2. As imagens mentais são vistas aqui enquanto possíveis imagens que se formam de modo subjetivo no momento de diálogo existente entre o eu-espectador e a imagem-obra proposta pelo outro-produtor da mesma. Greiner (2005, p. 8o) diz que "quando entramos em contato com objetos (pessoas, lugares, ações), através de um movimento que vai do exterior para o interior ou vice-versa (quando, por exemplo, reconstituímos objetos através da memória), estamos sempre construindo imagens. (...). Todos os símbolos em que podemos pensar são necessariamente imagens mentais. Mesmo os sentimentos que constituem o pano de fundo de toda vida mental, são também imagens somatossensoriais que dizem respeito a diversos aspectos dos estados corporais. São os sentimentos obsessivamente repetidos que desenvolvem o sentimento de si-mesmo, durante o ato de conhecer".

Recebido em: 31/03/2011

Aceito em: 11/o6/2011 


\section{CRISTIAN POLETTI MOSSI}

cristianmossi@gmail.com

Doutorando do Programa de Pós-Graduação em Educação (PPGE) da Universidade Federal de Santa Maria/RS (UFSM) pela linha de pesquisa 'Educação e Ates'. Bolsista CAPES. Mestre em Artes Visuais pelo Programa de Pós-Graduação em Artes Visuais (PPGART) com bolsa CAPES/Reuni integral, Especialista em Design para Estamparia, Bacharel e Licenciado em Desenho e Plástica pela mesma instituição. Membro pesquisador do Grupo de Estudos e Pesquisas em Arte, Educação e Cultura (GEPAEC).

\section{MARILDA OLIVEIRA DE OLIVEIRA}

marildaoliveira27@gmail.com

Professora do Programa de Pós Graduação Educação (PPGE/CE/ UFSM). Doutora em História da Arte (1995) e Mestre em Antropologia Social (1990), ambos pela Universidad de Barcelona - Espanha. Coordenadora do GEPAEC - Grupo de Estudos e Pesquisas em Arte, Educação e Cultura - Diretório CNPq. Representante da ANPAP no RS e Editora da Revista Digital do LAV. 